\title{
Avaliação da qualidade de água para abastecimento público do Município de Nova Iguaçu
}

\author{
Quality assessment of the public water \\ supply in Nova Iguaçu, Rio de J aneiro
}

Paulo Soares d'Aguila 1

Odir Clécio da Cruz Roque 1

Carlos Alberto Silva Miranda 1

Aldo Pacheco Ferreira 1

\footnotetext{
1 Departamento de Saneamento e Saúde Ambiental, Escola Nacional de Saúde Pública, Fundação Oswaldo Cruz. Rua Leopoldo Bulhões 1480 5 o andar, Rio de Janeiro, RJ 21041-210, Brasil.
}

Abstract This study proposes to develop methodol ogies for public water supply quality control by implementing evaluation and control mechanisms and enhancing environmental health surveillance decision-making. These objectives were based on data for waterborne di seases recorded at the Rio de Janei ro State Health Department. We sel ected the following neighborhoods: Posse (1st Township) and Caioaba (5th Township), with dissimilar situations, allowing us to producea model of water supply coverage in the Muni ci pality of Nova Iguaçu, Rio de Janeiro State. The study underscored the poor quality of the water supply in the two townships, since $61 \%$ of the samples were positive on bacteriological examination, showing the undesi rable effects of differential sanitation, especially in developing countries.

Key words Water Quality; Sanitation; Water Supply; Pseudomonas aeruginosa

Resumo Esta pesquisa propõe o desenvolvimento de metodologias para controle de qualidade da água de abastecimento público tanto pela operaci onalização de mecanismos de avaliação e controle quanto pela significativa contribuição para a tomada de deci são na vi gilância em saúde ambi ental. Tais obj eti vos encontraram fundamento em dados de acometi mento de doenças de vei culação hídrica registrados na Secretaria Estadual de Saúde. Foram sel ecionados os bairros da Posse (primeiro Distrito) e Caioaba (5o Distrito), os quai s mostraram situações díspares, o que permitiu modelar a situação de cobertura no Município de Nova I guaçu, no Rio de Janeiro. O trabalho tornou patente o comprometimento da qual idade da água dos distritos estudados, uma vez que $61 \%$ das amostras apresentaram posi ti vação nos exames bacteriológicos, evidenciando os efeitos indesejáveis do saneamento diferenciado que desponta, sobretudo, nos países em desenvolvimento.

Palavras-chave Qualidade da Água; Saneamento; Abastecimento deÁgua; Pseudomonas aeruginosa 
Introdução

O propósito primário para a exigência de qualidade da água é a proteção à saúde pública. Os critérios adotados para assegurar essa qualidade têm por objetivo fornecer uma base para o desenvolvimento de ações que, se propriamente implementadas junto à população, garantirão a segurança do fornecimento de água através da eliminação ou redução à concentração mínima de constituintes na água conhecidos por serem perigosos à saúde.

Visando à avaliação da qualidade da água de abastecimento, foi implementado o desenvolvimento de tecnologias como proposta metodológica para monitoramento de água em municípios abrangi dos pelo Sistema Único de Saúde (SUS). Isto se justifica diante dos resultados apontados pelos índices de morbi-mortalidade referentes a enfermidades de veiculação hídrica, caracterizadas pela ingestão de água contaminada por microorganismos, inter-relacionando orientações fornecidas pela Organização Mundial da Saúde (WHO, 1996), no que diz respeito à execução de programas com objetivos de redução da morbidade decorrentes de doenças diarréicas, com a melhoria dos cuidados prestados às crianças, a vigilância epidemiológica e a qualificação de sistemas de abastecimento de água.

No Município de Nova Iguaçu, os bairros Posse (10 distrito) e Caioaba (5o distrito) foram escolhidos por representarem situações opostas não só quanto ao abastecimento d'água, como também no desenvolvimento sócio-econômico. O bairro da Posse é mais desenvolvido, apresenta maior população e é considerado o melhor distrito do município não só quanto ao aspecto sanitário, mas também pelo maior número de escolas e melhor atendimento médico-hospitalar - nele está local izado o melhor e maior hospital da baixada, o Hospital da Posse -, assim como, de acordo com dados da Secretaria deVigilância Sanitária do Estado do Rio de Janeiro, por apresentar melhores resultados nas análises feitas pela Companhia Estadual de Água e Esgoto (CEDAE) na água de abastecimento público. O bairro de Caioaba representa a situação mais crítica em todos os aspectos.

$A$ água é essencial à manutenção da vida. $A$ proteção de contaminações no fornecimento de água é a primeira linha de defesa (Dahi, 1992). Quase invariavelmente, o melhor método de assegurar água adequada para consumo consiste em formas de proteção, evitando-se contaminações de dejetos animais e humanos, os quais podem conter grande variedade de bactérias, vírus, protozoários e helmintos. Fa-
Ihas na proteção e no tratamento efetivo expõem a comunidade a riscos de doenças intestinais e a outras doenças infecciosas (Bromberg, 1995; Heller, 1998). Os riscos à saúde relacionados com a água podem ser distribuídos em duas categorias principais: 1) riscos relativos à ingestão de água contaminada por agentes biológicos (vírus, bactérias e parasitas), através de contato direto ou por meio de insetos vetores que necessitam da água em seu ciclo biológico; 2) riscos derivados de poluentes químicos ea, em geral, efluentes de esgotos industriais (Charriere et al., 1996; Kramer et al., 1996).

Os principais agentes biológicos descobertos nas águas contaminadas são as bactérias patogênicas, os vírus e os parasitas. As bactérias patogênicas encontradas na água e/ ou alimentos constituem uma das principais fontes de morbidade em nosso meio. São as responsáveis pel os numerosos casos de enterites, diarréias infantis e doenças epidêmicas (como a febre tifóide), com resultados freqüentemente letais. Os vírus mais comumente encontrados nas águas contaminadas por dejetos humanos, entre outros, são os da poliomielite e da hepatite infecciosa. Dentre os parasitas que podem ser ingeridos através da água destaca-se a Entamoeba histolytica, causadora da amebíase e suas complicações, inclusive para o lado hepático. É encontrada sobretudo em países quentes e em locais onde existem más condições sanitárias. Na Tabela 1 podem ser observadas as principais doenças relacionadas à ingestão de água contaminada e seus agentes causadores (WHO, 1996).

O controle de qualidade de água destinada ao consumo humano, desde os sistemas produtores (mananciais, captação, tratamento) aos sistemas de distribuição (reservatório, redes), normalmente é realizado pela empresa responsável de saneamento local e monitorada pelas Secretarias de Saúde Estaduais. Este monitoramento - estabelecido pela Portaria no 36/ GM (Brasil, 1990a) do Ministério da Saúde institui números mínimos de amostras ou planos de amostragem, além dos padrões para a água potável restritos ao trecho que se inicia na captação e se encerra nas ligações domiciliares dos consumidores.

Na verdade, não se sabe a qualidade de água nos reservatórios domiciliares, de onde o produto tratado e monitorado é realmente consumido pela população. A manutenção da qualidade da água distribuída exige recursos de pessoal especializado para chegar potável ao consumidor; no entanto, leigos no assunto administram, no dia-a-dia, os prédios e a maioria 
das resi dências. Estes, por sua vez, não são corretamente orientados para a necessidade de cuidados especiais de manutenção dos reservatórios prediais de água.

Os dados obtidos com este estudo permitem crer que sejam representativos da situação de abastecimento público de água no Brasil, país em desenvolvimento, cujas condições favorecem as conseqüências desastrosas do saneamento diferenciado. $\mathrm{Na}$ amostragem deste estudo foram incluídos casos específicos, tais como: concentração de pessoas, grande utilização de água, escolas públicas, água sendo consumida diretamente de reservatórios, enfatizando-se procedimentos que instituam uma metodologia de seleção prioritária de análise de águas de consumo, representativas de possibilidade de contaminação. Outro ponto de observação foi o estudo da interferência de Pseudomonas aeruginosa nas análises colimétricas fixadas como padrão pelo Ministério da Saúde para a contaminação da água de consumo humano. Ao mesmo tempo em que se examina a contaminação e a ocorrência de doenças, estabelecem-se dados de microrganismos que causam interferências nas análises colimétricas tanto pela capacidade de inibir crescimento de coliformes em meio de cultura quanto pelas suas características, na qualidade de patógeno oportunista, de resistência aos antibióticos e ao cloro (d'Aguila, 1996).

\section{Materiais e métodos}

A qualidade da água de abastecimento foi avaliada por meio de exames físico-químicos e microbiológicos (ABNT, 1987; Alves et al., 1992; APHA, 1995).

Para a realização das provas, foram coletadas duas seções de amostras nos dois sítios de estudo, em períodos distintos, com intervalo de 14 dias. Visava-se, com isso, analisar não só a qualidade da água de abastecimento, mas também a qualidade do fornecimento.

\section{Área de estudo - amostragem}

As amostras foram avaliadas no local da coleta e no laboratório de análises. As avaliações locais constaram de: aspecto, odor, cor, cloro residual e reação de Nessler. Em virtude do decaimento do teor de cloro, as amostras para estas análises foram submetidas a exames locais de cloro residual. O mesmo procedimento de análise local foi realizado quanto ao teste de Nessler, o qual evidencia positivamente ou negativamente contaminação por coliformes na
Tabela 1

Principais doenças relacionadas à ingestão de água contaminada e seus agentes causadores.

\begin{tabular}{ll}
\hline Doenças & Agente causador \\
\hline Cólera & Vibrio cholerae \\
Disenteria bacilar & Shiggella sp. \\
Febre tifóide & Salmonella typhi \\
Hepatite infecciosa & Vírus da Hepatite do tipo A \\
Febre paratifóide & Salmonella paratyphi A, B e C \\
Gastroenterite & Outros tipos de Salmonella, Shiggella, Proteus sp. \\
Diarréia infantil & Tipos enteropatogênicos de Escherichia coli \\
Leptospirose & Leptospirose sp. \\
\hline
\end{tabular}

amostra. Todas as amostras foram checadas quanto à presença de coliformes totais e fecais pelo método de tubos múltiplos ou membrana filtrante e ensaios de P. aeruginosa.

Em Caioaba foram recolhidas amostras em 39 logradouros, perfazendo um total de 142 análises de pontos de coleta, tais como: entrada do domicílio, ponto interno da habitação, caixa d'água, cisterna, além de poço, em algumas amostras. No bairro da Posse as amostras provieram de 27 logradouros, perfazendo um total de 149 análises de pontos de coleta, reiterando os mesmos pontos de coleta do logradouro anterior.

Determinaram-se, como parâmetros de coleta, as seguintes condições: consumidores de água fornecida exclusivamente pela CEDAE; consumidores com auto-abastecimento, quando não havia outra fonte; possibilidade de acesso e vistoria das instalações; e possibilidade de coleta de amostras para análises bacteriológicas prévias, ou seja, em ponto anterior ao da mistura com água da caixa d'água. As análises laboratoriais foram elaboradas a partir de amostras que perfizeram, em média, três amostras por $\mathrm{km}^{2}$.

\section{Procedimentos para operacionalização das coletas}

Em virtude das condições de doenças e dados secundários, procedeu-se às diretrizes de coleta, nos bairros e logradouros da região, localizando-os via satélite com o auxílio do general position system (GPS), procurando-se centralizar em lugares notáveis e de grande movimentação, como, por exemplo, escolas, creches, hospitais, clubes, restaurantes, hotéis, motéis, instituições públicas; enfim, todos os locais de afluência humana (de trabalho ou de lazer), que 
utilizam reservatórios prediais para grande consumo, como também residências em locais previamente estabelecidos por plantas baixa de situação, em especial, por serem locais de permanência por longo período de tempo.

Tomou-se em conta o percentual populacional de cobertura de abastecimento de água, de cobertura de rede de esgoto, dados de setores censitários da Fundação Instituto Brasileiro de Geografia e Estatística (IBGE), bem como a área de influência do sistema de abastecimento.

\section{Parâmetros de avaliação da pesquisa}

É importante ressaltar que somente as amostras com índice colimétrico igual a zero e ausência de pseudomonas foram consideradas próprias para consumo humano. No tocante ao nível de cloro, a faixa de aceitabilidade em análises de água dá-se pela faixa de 1,5 a 3,0 mg/ ml.

$\mathrm{Na}$ avaliação local, julgou-se ser reservatório em boas condições aquele que não estava sujeito à infiltração de águas servidas, pluviais ou proveniente de refluxos, sem possibilidade de rachaduras (principalmente as cisternas), que apresentavam construção adequada e com proteção contra a penetração de insetos. Não se considerou, no caso, a limpeza periódica dos reservatórios, buscando-se, neste momento, os dados reais da pior condição da utilização da água tratada.

Dessa maneira, as avaliações locais tomaram em conta: a verificação do estado de conservação das tampas; as possibilidades de infiltração de águas servidas do solo ou águas a céu aberto; o exame da possibilidade de penetração de insetos; verificação de rachaduras ou desmoronamentos internos; e a presença de aves nos reservatórios superiores. É preciso ressaltar que, mesmo nos reservatórios tidos como inadequados, foram coletadas amostras para efeito de avaliação da contaminação e sua conotação com os índices de doenças de veiculação hídrica.

\section{Descrição do sítio em estudo}

O Município de Nova I guaçu foi criado a 15 de janeiro de 1833, instalando-se sua sede às margens do rio que lhe deu o nome. Compreendia as seguintes paróquias (distritos): Jacutinga (nome dos índios da região), Pilar, Meriti, Marapicu e Iguassu (em tupi: muita água). Ao progresso deve ser creditada a estrada Real do Comércio, primeira via aberta no Brasil para o escoamento do café do interior do país para os trapiches e portos do rio I guassu (que desemboca na Baía de Guanabara). O café daria ao município outra estrada, a estrada de ferro de Dom Pedro II (1858), responsável direta pela decadência de Iguassu, passando então a ser chamada, a partir de 1891, de Iguassu Velha. Neste ano, a sede do município foi transferida para o arraial de Maxambomba servida pela dita ferrovia. Finalmente, em 1916, Maxambomba passa a ser chamada de Nova I guaçu.

O território de Nova I guaçu possui área de 566,6 km², sendo que 198 km², ou seja, 35\% da cidade é coberta de floresta tipo Mata Atlântica, formando assim duas importantes áreas de preservação ecológica: a Reserva Biológica de Tinguá - reconhecida pela United Nations Educational, Scientific and Cultural Organization (UNESCO) como patrimônio da humanidade e a Área de Proteção Ambiental da Serra de Madureira - considerada pela UNESCO como Reserva de Biosfera. O município, portanto, possui potencialidade para explorar o turismo ecológico como fonte de recursos para o desenvolvimento. Neste sentido, existem propostas de criação de parque ecológico na região da Gleba Modesto Leal com, aproximadamente, $11 \mathrm{mi}$ Ihões de $\mathrm{m}^{2}$.

Embora na atualidade apresente vocação para o turismo ecológico, o município foi consolidado a partir do desmatamento para a exploração de lenha, carvão e madeiras de lei, bem como da plantação de cana de açúcar e, mais tarde, de laranjas. A fase áurea da citricultura imperou desde 1930 até cerca de 1939, quando a Segunda Grande Guerra interrompeu a exportação da fruta, a qual se tornou insignificante em meados de 1956. Desde então, os laranjais cederam espaço aos loteamentos e às atividades industriais, que se expandiram, fazendo com que a população atingisse o número de 800.000 habitantes, conforme dados censitários do IBGE de 1996 (IBGE, 1996).

A extensão norte-sul de 36 km e leste-oeste de $19 \mathrm{~km}$ é cortada por diversos rios de importância econômica e social para os habitantes do Estado. Fazem parte de seu território os rios Guandu, da Bota, Sarapui, Tinguá, Capivari. Destaca-se o rio Guandú como fonte principal de fornecimento de água para abastecimento da população da cidade do Rio de Janeiro e Baixada Fluminense. Apesar de as temperaturas ambientes atingirem valores elevados no verão, a temperatura média anual é agradável, situando-se em torno de $21,8 \circ \mathrm{C}$. O município é limitado pelas cidades do Rio de Janeiro, Nilópolis, São João de Meriti, Duque de Caxias, Belford Roxo, Seropédica, Queimados, Japeri e Miguel Pereira, possuindo malha rodoviária razoável.

Para análises posteriores deste artigo, explicitam-se indicadores de saúde da região, ten- 
do-se como fonte o IBGE, do ano de 1998 (IBGE, 1998). Os Hospitais credenciados são oito e há 110 Unidades credenciadas, quatro Unidades mistas e 51 Mini-Postos de Saúde. As internações em hospitais credenciados no ano em foco foram 50.767 e é 48 o índice de Mortalidade Infantil por 1.000 habitantes.

\section{Resultados}

As tabelas explicitam os resultados de todas as análises da água de abastecimento e de poço do logradouro de Caioaba e do logradouro de Posse (Tabelas 2, 3 e 4). Nelas são demonstrados os quantitativos das análises de água, evidenciando o teor de microorganismos (coliformes totais, coliformes fecais, pseudomonas) e o grau de cloração. A Tabela 2 aborda a presença de coliformes. A Tabela 3 faz estudo comparativo referente à presença de cloro e sua dosagem, relacionando este grau ao nível de contaminação observada. A Tabela 4 discorre sobre análises de Pseudomonas aeruginosa.

Diante dos parâmetros evidenciados nas tabelas anteriormente descritas no tocante ao grau de contaminação, devido ao mau acondicionamento ou à contaminação residual na água de abastecimento, optou-se por analisar o teor de cloro livre na água de abastecimento. Para esta análise, duas coletas de água foram feitas no mesmo domicílio, com intervalo de tempo de 14 dias entre as coletas. A Figura 1 relata a variação encontrada na água de abastecimento, evidenciando os valores médios de abastecimento com análise estatística. Objetivou-se evidenciar o perfil de distribuição da água de abastecimento pela regressão linear dos dados (Saville \& Wood, 1996).

O gráfico denota que, quanto ao teor de cloro livre, somente $31,88 \%$ das amostras obtiveram valores dentro da faixa de aceitabilidade em uma análise e que apenas $11,59 \%$ das amostras exi biram resultados dentro da faixa aceitável nas duas análises; entretanto, 43,47\% das amostras não obtiveram valores dentro da faixa de aceitação, nas análises 1 e 2 . O perfil da curva obtida para valor médio das concentrações expressa valor de pico de apenas 1,6 mg/ml.

\section{Discussão}

Os resultados sinalizam a existência de condições favoráveis ao desenvolvimento de acometimentos diarréicos na população, sobretudo nos extremos (crianças, idosos) por não terem estes um sistema imunológico que funcione
Tabela 2

Dados de Caioaba e Posse quanto a presença bacteriana observada nas análises de qualidade de água.

\begin{tabular}{lcc}
\hline Distrito/Análises & Quantitativo & Positivas \\
\hline $\begin{array}{l}\text { Caioaba } \\
\text { Coliformes }\end{array}$ & 120 & 56 (coliforme total) \\
& & 22 (coliforme fecal) \\
Pseudomonas & 22 & 10 \\
Total & 142 & 88 \\
& & 60 (coliforme total) \\
Posse & 124 & 25 (coliforme fecal) \\
Coliformes & & 6 \\
Pseudomonas & 25 & 91 \\
Total & 149 & \\
\hline
\end{tabular}

Tabela 3

Dados de Caioaba e Posse quanto aos índices de cloro e o quantitativo de contaminação das amostras.

\begin{tabular}{lcc}
\hline Distrito/Nível de cloro & Quantitativo & Contaminadas \\
\hline Caioaba & 18 & 17 \\
0 & 18 & 10 \\
Cloro $\leq 0,2$ & 61 & 20 \\
$0,2<$ Cloro $\leq 1,2$ & 16 & 2 \\
Cloro $>1,2$ & 113 & 49 \\
Total & & \\
Posse & 16 & 14 \\
0 & 22 & 14 \\
Cloro $\leq 0,2$ & 41 & 12 \\
$0,2<$ Cloro $\leq 1,2$ & 35 & 12 \\
Cloro $>1,2$ & 114 & 52 \\
Total & & \\
\hline
\end{tabular}

ativamente nem resistência a infestações, razão pela qual, caso contaminados, a doença se apresentará com maior severidade. Como desdobramento, é importante ressaltar que as contaminações evidenciadas nas pesquisas efetuadas apontam ser causa iminente de diarréias e hepatites no município. Confrontando os dados oriundos da Secretaria Municipal de Saúde de Nova I guaçu - onde foram notificados 203 casos de hepatite A e 107 casos de diarréias em 1998 (SES-RJ, 1998) - com o resultado da qualidade da água de Caioaba e Posse, conclui-se que, apesar de estes distritos estarem em con- 
Tabela 4

Dados de Caioaba e Posse quanto a análises das amostras para Pseudomonas aeruginosa.

Distrito/Tipo Análises Análises positivas com cloro Positivas
$\left[\begin{array}{cccc}0 & 0,05 & 0,1 & 0,6\end{array}\right.$

\begin{tabular}{lrrrrrr} 
Caioaba & & & & & & \\
Abastecimento & 19 & 3 & 1 & 1 & 1 & 7 \\
Poço & 3 & 7 & 1 & 1 & 1 & 10 \\
Total & 22 & & & & & \\
Posse & & 2 & 1 & 1 & - & 4 \\
Abastecimento & 21 & 2 & - & - & - & 2 \\
Poço & 4 & 4 & 1 & 1 & - & 6 \\
Total & 25 & & & & & \\
\hline
\end{tabular}

Figura 1

Perfil médio do teor de cloro livre na distribuição da água de abastecimento.

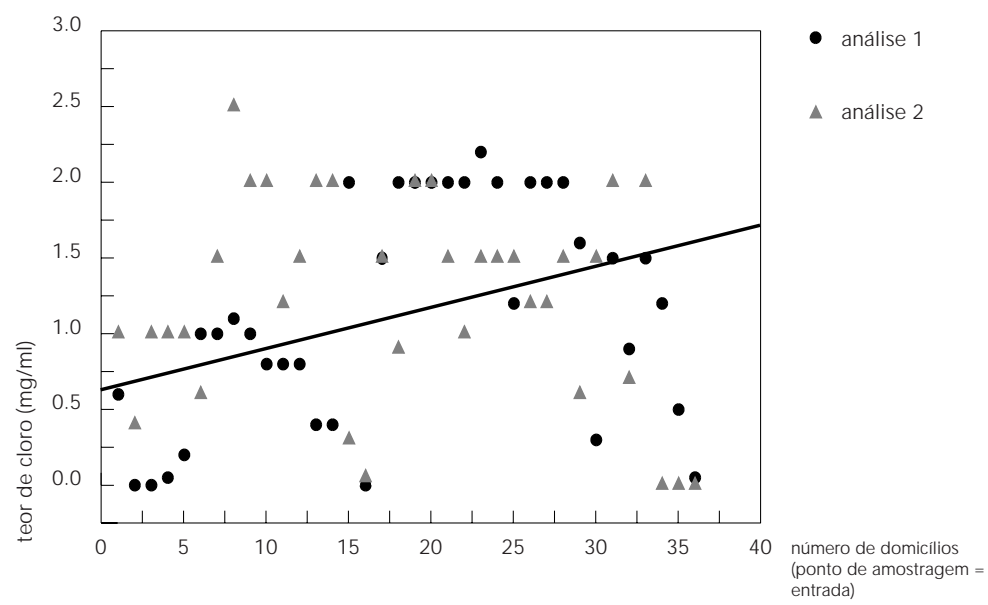

dições opostas no planejamento municipal, demonstram aparentemente evidências igualitárias de acometimento de doenças de veiculação hídrica em virtude de receberem a água de abastecimento de fonte comum.

Ficou manifesta a falta de orientação à população quanto à necessidade de utilizar água somente da fornecedora, sem outras misturas (água de poço ou de mananciais), fato que ocorreu em $4,54 \%$ dos pontos de coleta - dentre estes, alguns expressivos, o que aumentou a preo- cupação -, justificado pelo não fornecimento de água com regularidade. Por problemas financeiros, $7,57 \%$ dos pontos de coleta utilizam apenas água de poço, registrando-se, nessas análises, presença de contaminação (coliformes totais, coliformes fecais e pseudomonas) em 97,7\% em decorrência da não cloração aditiva da água e pela demonstração de contaminação do lençol freático como subproduto de ocupações desordenadas e de mau uso do solo. Outro aspecto preocupante reside em $61,51 \%$ dos pontos de coleta apresentarem contaminação, indicando que o sistema de desinfecção da água na estação de tratamento não é suficiente para garantir a permanência do cloro livre, que mantenha a potabilidade da água nos domicílios.

Desses dados pode-se inferir fatores de ris$\mathrm{co} /$ morbidade na população de acometimentos de doenças de veiculação hídrica. De acordo com o Programa de Organização Mundial da Saúde reconhece-se que as diarréias (enterites, disenterias) constituem uma das maiores causas de morbi-mortalidade em crianças na faixa de 0 a 4 anos nos países em desenvolvimento; desses, 3 a $4 \%$ redundaram em morte. Os estudos comprovam que a doenças diarréicas são responsáveis anual mente por milhões de óbitos de crianças nos países em desenvolvimento, além de retardarem o crescimento físico e prejudicarem a qualidade da vida das que sobrevivem, por causa de escassez de comida, recusa de alimento e má absorção. A doença é mais grave ainda nos desnutridos, nos quais leva à desidratação e ao êxito letal. No Brasil, a enterite e outras doenças diarréicas ocupam o primeiro lugar como causa de óbito em todas as idades, apesar do elevado número de mortes consideradas sem assistência médica, óbitos mal definidos e sub-registro.

Situações como essas fizeram com que a Organização Mundial da Saúde (WHO, 1996), revendo a extensão e gravidade do problema e os progressos científicos recentes, recomendasse a execução de um programa com o objetivo de reduzir a morbidade decorrente de doenças diarréicas pela melhoria dos cuidados prestados às crianças, vigilância epidemiológica e qualificação de sistemas de abastecimento de água.

Ficou evidenciado que a preservação da qualidade da água durante o período de sua permanência nos reservatórios prediais depende de boas condições físico-sanitárias. Em geral, os consumidores não estão informados da necessidade de manutenção, limpeza e higienização dos reservatórios e instalações prediais e, quando utilizam águas de outras fontes como complemento, não conhecem as limitações 
e a possi bilidade de estar contaminada. Os reservatórios domiciliares, com raríssimas exceções, encontravam-se em péssimas condições de limpeza. Alguns moradores, residindo há mais de dez anos no local, declararam desconhecer a necessidade da limpeza. Em vista disso, é aconselhável que se inicie um trabalho de educação sanitária junto a essa comunidade. Afora isso, em alguns locais, principalmente da Posse, não existe abastecimento público de água. A solução é encontrada individualmente através de poços tubulares ou de carros-pipa. Nos resultados das análises dos poços evidenciou-se contaminação significativa, inclusive com presença de $\mathrm{P}$. aeruginosa.

De acordo com a Constituição Federal, em seu artigo 30 (Brasil, 1988), é competência dos municípios organizar e prestar, diretamente ou sob regime de concessão ou permissão, os serviços de interesse local. Tal atribuição confere à instância municipal a responsabilidade da gestão dos serviços de saneamento, embora não exclua os níveis estadual e federal de atuar no setor seja no campo de estabelecimento de diretrizes, seja no da legislação ou da assistência técnica. É ainda necessário um envolvimento dessas instâncias em situações relacionadas ao saneamento, como as que apresentam caráter que abrangem mesmo as três instâncias, e aquelas associadas à gestão dos recursos hídricos.

Exceto poucas e incompletas iniciativas municipais e estaduais, não existe legislação em vigor que estabeleça as normas de uso e conservação dos reservatórios prediais de água, definindo com clareza as competências e responsabilidades. Os custos de análises, de manutenção, tal como a desinformação e o descaso dos responsáveis públicos, levam a população a consumir água contaminada apesar de todos os problemas de saúde pública que daí podem advir. É interessante ressaltar que a quase totalidade de microorganismos é incapaz de viver em sua forma adulta ou reproduzir-se fora do organismo que lhe serve de hospedeiro, tendo, portanto, vida limitada quando se encontra na água, isto é, fora de seu habitat natural. Entretanto, como ficou patente nas análises, além da falta de manutenção dos reservatórios, existe contaminação sistemática da rede de abastecimento, subentendendo possíveis infiltrações nas tubulações e cloração inadequada.

Embora haja uma parcela razoável de empresas privadas prestadoras de serviços de saneamento, controle e higienização de reservatórios de água, é irrisória a quantidade de serviços e profissionais real mente especializados no assunto que atuam no segmento. Em geral, esses serviços são executados por pessoas leigas no assunto, ou por empresas de limpa-fossas, que trazem mais riscos do que soluções.

Por sua vez, há a necessidade de estabelecer diferença entre reservatórios para uso doméstico e aqueles de uso semi-coletivo e coletivo. Os primeiros abastecem número limitado de pessoas, e o responsável é da própria família. Nos semi-coletivos, a responsabilidade está dividida entre síndico e condôminos e, por último, as escolas públicas, creches e outras instituições públicas que ficam a cargo dos responsáveis pelo setor que, na verdade, não realizam vistoria, colocando em risco grande número de pessoas. Na outra ponta, as empresas distribuidoras de água (companhias estaduais ou municipais de saneamento) podem ter sérios problemas em caso de incidência de doenças de veiculação hídrica, pela comprovada contaminação da água, apesar de estar aduzindo água de boa qualidade até a residência do consumidor, mesmo que a contaminação tenha ocorrido no ramal interno do consumidor.

O atual código do consumidor, na Lei no 8.078 de 11/ 09/ 1990 (Brasil, 1990b), atua em defesa do usuário, já que a empresa fornecedora poderá ser obrigada a provar em juízo que prestou ao consumidor "informação adequada e clara sobre os riscos" que a água pode ocasionar ao ser consumida (Direitos Básicos, Art. 6, Inciso III). A mesma Lei, quando dispõe "Da responsabilidade", determina que o produtor responde independentemente de existência de culpa pela reparação dos danos causados aos consumidores por informações insuficientes e/ ou inadequadas (Art.12). Pelos motivos expostos, fica claro que existe legislação pertinente ao abastecimento de água para consumo humano, abrangendo principalmente a distribuição fora das residências, sem levar em consideração o consumo interno aos prédios, fato que concorre para grande número de doenças facilmente controladas por ações simples de saneamento.

Os padrões de potabilidade são definidos no Brasil pelo Ministério da Saúde, na Portaria no 36/ 90 (Brasil, 1990a); portanto, o município deve obedecer às normas vigentes de água destinada ao consumo humano. Entretanto, o controle da potabilidade da água fica restrito na distribuição geral até a chegada aos domicílios. A qualidade e conservação a partir da entrada da água (hidrômetros) no ramal predial é de responsabilidade do proprietário da residência e/ ou do condomínio no caso de prédios ou áreas condominiais. A maioria dos prédios ou residências possuem reservatórios de acumu- 
lação de águas para consumo. A portaria define a vigilância da qualidade da água como o "conjunto de atividades de responsabilidade da autoridade sanitária estadual competente, com a finalidade de avaliar a qualidade da água distribuída e de exigir a tomada de medidas necessárias, no caso da água não atender ao padrão de potabilidade". Neste caso, o conceito de água distribuída não tem a mesma qualidade e significado de água verdadeiramente consumida. As águas entre o hidrômetro de entrada e os reservatórios prediais, em muitos casos, recebem contribuições de águas como complemento e, até a chegada às torneiras, passam por reservatórios prediais, onde ocorre grande incidência de contaminação da água. Nestes casos, a água verdadeiramente consumida não está sob controle. A manutenção de reservató- rios prediais realizada pelos usuários leva a competência aos próprios consumidores do controle da água acumulada. Em termos de saúde, esta postura é totalmente inadequada, já que, o consumidor normal mente é leigo no assunto e o exame de controle na maioria das vezes está fora do poder aquisitivo da população pobre.

Ficou claro nestas pesquisas que os problemas da qualidade da água de abastecimento e as conseqüências do uso desta necessitam da correlação de medidas de inspeção que vão desde a água da fornecedora e a de uso, sem aumento do quantitativo de análises, mas sim da abrangência da amostragem. Com isso, acredita-se que os índices de acometimentos de infecções de veiculação hídrica tenderão a limites baixos.
Referências

ABNT (Associação Brasileira de Normas Técnicas) 1987. NBR 9.898. Preservação e Técnicas de Amostragem de Efluentes Líquidos e Corpos Receptores. Rio de Janeiro: ABNT.

ALVES, M. N.; M OLINA, A. G. \& SANCHEZ, P. S., 1992 Exame Microbiológico da Água. São Paulo: Companhia de Tecnologia de Saneamento Ambiental.

APHA (American Public Health Association), 1995. Standard Methods for the Examination of theWater and Wastewater. 19th Ed. New York: APHA

BRASI L, 1988. Constituição (1988). Constitui ção da República Federativa do Brasil. Brasília: Senado Federal.

BRASIL, 1990a. Portaria no 36/GM. Padrão de Potabilidade da Água Destinada ao Consumo Humano. Brasília: Ministério da Saúde.

BRASI L, 1990b. Lei no 8.078. Código do Consumidor. Diário Oficial da República Federativa do Brasil, Brasília, DF, capítulo III, inciso III, artigos 6 e 12, 11 set. বhttp://www.jol.com.br/legis/codigos/ coddecon/tt01cc01.htm>

BROMBERG, M., 1995. Safe drinking water: Microbial standards help ensure water quality for consumers. 14 jun. 1998 <tttp:// hermes.ecn.purdue. edu/cgi/convwqtest?/ ru-7.il.ascii>.

CHARRIERE, G.; M OSSEL, D. A. A.; BEAUDEAU, P. \& LECLERC, H., 1994. Assesment of the marker value of various components of the coli-aerogenes group of Enterobacteriaceae and of a selection of Enterococcus spp. For the official monitoring of drinking water supplies. Journal of Applied Bacteriology, 76:336-344.
D'AGUILA, P. S., 1996. Pseudomonas aeruginosa como Indicador em Análises Bacteriológi cas de Águas de Abastecimento Público. Dissertação de Mestrado, Rio de Janeiro: Escola Nacional de Saúde Pública, Fundação Oswaldo Cruz.

DAHI, E., 1992. Water Supply in Developing Countries: Problems and Solutions. Lyngby: Eds. Technical, University of Denmark.

HELLER, L., 1998. Saneamiento y Salud. Washington, D.C.: CEPIS/OPS.

IBGE (Fundação Instituto Brasileiro de Geografia e Estatística), 1996. Anuário Estatístico do Brasil, Volume 56. Rio de Janeiro: IBGE.

IBGE (Fundação Instituto Brasileiro de Geografia e Estatística), 1998. Anuário Estatístico do Brasil, Volume 58. Rio de Janeiro: IBGE.

KRAMER, M. H.; HERWALDT, B. L.; CRAUN, G. F.; CALDERON, R. L. \&JURANEK, D. D., 1996. Waterborne disease: 1993 and 1994. Journal of American Water Work Association, 88:66-80.

SAVILLE, D. J. \& WOOD, G. R., 1996. Statistical Methods. New York: Springer-Verlag.

SES-RJ (Secretaria de Estado da Saúde do Rio de Janeiro), 1998. Dados sobre Diarréia Infantil no Estado do Rio deJaneiro. Rio de Janeiro: SES-RJ.

WHO (World Health Organization), 1996. Guidelines for Drinking-Water Quality. Geneva: WHO. 